\title{
ENTREVISTA COM O HISTORIADOR MEDIEVALISTA PORTUGUÊS PROFESSOR DOUTOR CARLOS GUARDADO DA SILVA DA UNIVERSIDADE DE LISBOA, PORTUGAL
}

\section{VERONICA APARECIDA SILVEIRA AgUiAR*}

Veronica Aparecida Silveira Aguiar [V. A.] - Professor Carlos Guardado da Silva, antes de tudo, gostaríamos de agradecer a disponibilidade em nos conceder esta entrevista e ressaltar que é com grande prazer que a Revista Fronteiras \& Debates o tem como entrevistado. A profissão de historiador foi uma escolha? Poderia nos relatar brevemente sua trajetória?

Carlos Guardado da Silva [C. G.] - Prezada Professora Verônica Aguiar, sou eu quem muito agradece, pois é um prazer poder conversar consigo e conhecê-la, e uma honra ser entrevistado para a revista Fronteiras \& Debates, de modo a poder partilhar algumas ideias com os nossos colegas historiadores brasileiros, mediavalistas ou não.

Para começar, a primeira pergunta já é difícil, pois tenho dúvidas se, em algum momento, alguém pode decidir que quer ser historiador. Em Portugal, por regra, e ao longo de toda a vida, é difícil ser-se historiador, por profissão, isto é, em exclusividade, uma vez que a carreira de investigador praticamente não existe. Consegui sê-lo em acumulação, quer como técnico superior do arquivo municipal de Torres Vedras, desde 1997, quer como professor da Faculdade de Letras da Universidade de Lisboa, desde 2007. Desde início, apostei nos estudos, pensando etapa-a-etapa - licenciatura em história, mestrado em história medieval e doutoramento em história medieval -, mas mantendo o trabalho profissional, apesar de ter tido a oportunidade de me dedicar em exclusividade à investigação durante 6 anos, fruto de duas bolsas de mérito, da Junta Nacional de Investigação Científica e Tecnológica (JNICT) e da Fundação para a Ciência e a Tecnologia (FCT), respetivamente para o mestrado e o doutoramento. Terminado o doutoramento, optei for fazer uma Pós-graduação em ciências documentais - variante de arquivo ( 2 anos), um curso profissionalizante, de modo a poder garantir trabalho, tendo depois feito a Pós-graduação em ciências documentais - variante de biblioteca e documentação, trabalhando em simultâneo. O gosto pela história ficou desde a con-

\footnotetext{
* Professora de História Antiga e Medieval do Departamento de História e Docente do Programa de PósGraduação em Estudos Culturais da Universidade Federal de Rondônia. Doutora em História Social pela Universidade de São Paulo (USP).
} 
clusão da licenciatura, tendo acrescido também o gosto pela ciência da informação, que em Portugal integra a arquivística e a biblioteconomia, a partir do momento em que comecei a trabalhar no arquivo municipal de Torres Vedras, em 1997, dividindo hoje os meus interesses relativos à investigação entre a história e a ciência da informação. É, aliás, nesta área que sou docente na Faculdade de Letras da Universidade de Lisboa, em que dirijo o mestrado em ciências da documentação e informação, na mesma área em que fiz a agregação em ciência da informação, a última prova académica em Portugal.

V. A. - Quais foram os desafios de historiador enquanto diretor do Arquivo Municipal de Torres Vedras? Poderia mencionar as motivações que o levaram a pesquisar no Arquivo Municipal de Torres Vedras?

C. G. - Em primeiro lugar, foi necessário criar o próprio serviço de arquivo, de modo a promover o seu acesso, com a sua abertura, instituindo-o como unidade orgânica do município. Foi necessário muito trabalho, de uma equipa, que é mais do que o responsável, e com o apoio, desde início, do executivo. Depois, no exercício das competências que cabem a um arquivo municipal, foi possível cruzar os interesses do arquivista com os do historiador, mas nunca os confundindo, promovendo a investigação e realizando encontros científicos em que os resultados pudessem ser apresentados e discutidos, sobre Torres Vedras e não só, com recurso à documentação aí acondicionada, mas também de outros arquivos. No papel de responsável pelo arquivo, fiz investigação sobre a dcumentação, mas promovi igualmente a realização de inúmeros estudos desenvolvidos por outros investigadores. Nesse âmbito, contribuí para a definição de uma política editorial para o município e criei um encontro científico anual, internacional desde a 11. ed edção, em 2018 já na 21. a edição, - o Turres Veteras - uma coorganização, desde início, da Universidade de Lisboa e do Município de Torres Vedras, que publica anualmente as atas em livro em coedição com as Edições Colibri.

O meu gosto pela história local deve-se, em primeiro lugar, ao Professor Pedro Gomes Barbosa, meu professor e orientador de mestrado e doutoramento, com quem aprendi o verdadeiro valor da história regional e local para a compreensão da história nacional, sem a qual o conhecimento desta é menor, bem como distintos são os ritmos da história nacional e das vivências quotidianas, cujo pulsar só é percetível no local. Depois, 
este gosto reforçou-se com as funções no arquivo municipal e como colaborador do Instituto de Estudos Regionais e do Municipalismo Alexandre Herculano, de que o Professor Pedro Gomes Barbosa é diretor.

V. A. - Nas últimas décadas, em linhas gerais, na Europa e em especial em Portugal, como tem se desenvolvido o fomento de pesquisa na área de Ciências Humanas, em geral e, especificamente, em História?

C. G. - A pesquisa na área das Ciências Humanas e, particularmente, na história tem sido profícua e crescente, tendo permitido, em Portugal, o aparecimento de um conjunto interessante de sínteses, com a direção de grandes nomes da historiografia portuguesa. Refiram-se a História de Portugal (Alfa), de José Hermano Saraiva, a História de Portugal (Círculo de Leitores), de José Mattoso, a História de Portugal (Ediclube), de João Medina, a Nova História de Portugal (Presença), de Joel Serrão e António Henrique de Oliveira Marques, a que se devem juntar as sínteses de um só autor, nomeadamente a História de Portugal (Verbo), de Joaquim Veríssimo Serrão, e a História de Portugal (Caminho), de António Borges Coelho, esta ainda em curso, e, em um único volume, a recente História de Portugal (A Esfera dos Livros), de Rui Ramos, Bernardo Vasconcelos e Sousa e Nuno Gonçalo Monteiro. Acrescentem-se as histórias-síntese temáticas, de que são exemplo a História da Expansão Portuguesa (Círculo de Leitores), de Francisco Bettencourt e Kirti Chaudhurj, a Nova História da Expansão Portuguesa (Estampa), de Joel Serrão e António Henrique de Oliveira Marques, o Dicionário da Expansão Portuguesa (Afrontamento), de Francisco Contente Domingues, a História Religiosa de Portugal (Círculo de Leitores) e o Dicionário de História Religiosa de Portugal (Círculo de Leitores), ambos de Carlos Moreira Azevedo, a História da vida privada em Portugal (Círculo de Leitores), de José Mattoso, a Nova História Militar de Portugal (Círculo de Leitores), de Manuel Themudo Barata e Nuno Severiano Teixeira, a História das comunicações (Fundação Portuguesa das Comunicações), a História da Arte em Portugal (Presença), de Carlos Alberto Ferreira de Almeida, José Augusto França e Vítor Serrão, a História da Arte Portuguesa (Círculo de Leitores), de Paulo Pereira, a Arte portuguesa: da pré-história ao século XX (Fubu), de Dalila Rodrigues. E, ainda, a publicação, em Portugal, da História das Mulheres (Afrontamento), dirigida por Christiane Klapisch-Zuber, a História do corpo (Círculo de Leitores), sob a direção de Alain Corbin, Jean-Jacques Courtine e Georges Vigarello, e, acrescentem-se as coleções Reis de Por- 
tugal (Círculo de Leitores), coordenada por Roberto Carneiro, e Rainhas de Portugal (Círculo de Leitores), coordenada por Ana Maria S. A. Rodrigues, Isabel dos Guimarães Sá e Manuela Santos Silva, bem como as coleções Reis de Portugal e Rainhas e princesas de Portugal, ambas editadas pela Academia Portuguesa da História, sob a coordenação de Manuela Mendonça.

Neste momento, passada a fase das sínteses, ainda que se assinale a falta de outras sínteses temáticas, multiplicam-se as temáticas e as perspetivas com novas leituras e procura-se, uma cada vez maior cooperação nacional e internacional, valorizando-se o trabalho em equipa. Por outro lado, em Portugal e na Europa, como no mundo, fruto das imposições da escrita científica em inglês e em revistas internacionais, assim como no contexto do Acesso Aberto, a história portuguesa tende a tornar-se cada vez mais conhecida, sobretudo dos outros.

V. A. - Em 2017, o senhor publicou um artigo no Brasil sobre o patrimônio rural do mosteiro de São Vicente de Fora (Lisboa): séculos XII-XIII no Dossiê "História social da propriedade". Poderia tecer alguns comentários sobre a relação do patrimônio rural em Portugal?

C. G. - O tema do património rural em Portugal, na perspectiva da sua posse e dos direitos e rendimentos (eclesiásticos), é um tema relativamente bem estudado para a Idade Média, a partir de um grande volume de estudos, objeto de disertações de mestrado e doutoramento, a partir da documentação e cartórios diocesanos, monásticos (de que se destacam Santa Maria de Alcobaça, Santa Cruz de Coimbra e São Vicente de Fora) e das ordens religiosas. O seu estudo é, no fundo, resultado da promoção de estudos de História Rural, que muito deve a Virgínia Rau, António Henrique de Oliveira Marques, Iria Gonçalves, Maria Helena da Cruz Coelho e Pedro Gomes Barbosa. Foi o que aconteceu no meu caso, tendo efetuado a dissertação de mestrado sobre $O$ mosteiro de S. Vicente de Fora: a comunidade regrante e o património rural (Colibri), fundado em Lisboa, uma instituição filha do mosteiro regrante de Santa Cruz de Coimbra, estudo que desenvolvi para as centúrias de undecentos e duzentos.

Em Portugal, os estudos sobre o património rural, em que tenham por centro o estudo da propriedade, como era pretendido para o referido dossiê, e inclusivé no próprio título, são mais raros. Refiram-se, como exemplos, os estudos A propriedade da Ordem 
de Santiago em Palmela (Câmara Municipal de Palmela) a partir da visitações quinhentistas, de Cristina Vinagre Alves, Povoamento e propriedade: Entre o Zêzere e o Tejo: séc. XII-XIV (Colibri), de Maria da Graça Vicente, Propriedade fundiária e rendas da Coroa no reinado de D. Dinis (Faculdade de Letras da Universidade de Coimbra), de Maria Rosa Marreiros, e O património do mosteiro de Alcobaça nos séculos XIV e XV (Universidade Nova de Lisboa), de Iria Gonçalves.

V. A. - Com uma carreira consolidada como professor pesquisador e que tem como uma de suas temáticas o imaginário medieval, o senhor acredita que há um crescimento do interesse dos estudantes da pós-graduação em relação à temática mencionada, em Portugal?

C. G. - Existe um interesse crescente, em Portugal, pelos estudantes da pós-graduação, assim como da graduação pelo estudo do imaginário medieval, quer com formação em Literatura, quer com formação em História. Evidência disso é o crescente número de alunos, que se inscreve nestas unidades curriculares, esgotando, por exemplo, o numerus clausus de lugares em termos de graduação. Por outro lado, o imaginário medieval passou a ser objeto de encontros científicos, sendo temática de uma edição do Encontro Turres Veteras, e de diversas publicações, uma das quais tivemos o privilégio de coordenar (O imaginário medieval, Colibri). Também esse interesse devo ao Professor Pedro Gomes Barbosa, que me incutiu o gosto pelo imaginário medieval e, mormente, pelo imaginário da floresta, o contexto por excelência do ciclo arturiano, e que é, atualmente, em Portugal, o maior historiador da temática, na senda de José Mattoso (Poderes invisíveis: o imaginário medieval. Círculo de Leitores) e do historiador francês Jacques Le Goff (O maravilhoso e o quotidiano no ocidente medieval. Edições 70).

V. A. - O senhor poderia avaliar a atual produção portuguesa sobre a conquista de Ceuta e seu alcance entre os historiadores brasileiros?

C. G. - A atual produção historiográfica sobre a conquista de Ceuta é bem numerosa, devendo-se este volume à recente comemoração do 6.ำ centenário do acontecimento, sendo os centenários sempre propícios à revisitação dos temas e à renovação da historiografia. Refira-se, a título de exemplo, a juntar à obra pioneira Ceuta portuguesa: 1415-1656 (Instituto de Estudios Ceutíes, 1998), de Isabel Mendes Drumond Braga e 
Paulo Drumond Braga, ou à Ceuta: 1415: a conquista (Prefácio, 2002), de José Loureiro dos Santos), Ceuta, 1415: seiscentos anos depois (Livros horizonte, 2015), de Luís Miguel Duarte, Uma lança em África: História da conquista de Ceuta (A Esfera dos Livros, 2015), de Paulo Drumond Braga, 1415: a conquista de Ceuta (Manuscrito, 2015), de João Gouveia Monteiro e António Martins Costa, e Ceuta: primeira conquista de Portugal Além-Mar, (Monitorius, 2015), do jornalista Xavier de Figueiredo, a que podemos juntar D. Pedro de Meneses: O primeiro capitão de Ceuta (Sete Caminhos, 2008) (depois de D. Pedro de Meneses e a construção da Casa de Vila Real : 1415-1437. Colibri, 2004), de Nuno Silva Campos, e Henrique: O Infante (A Esfera dos Livros, 2009), de João Paulo Oliveira e Costa.

E acrescente-se os Cadernos do Arquivo Municipal: Ceuta (Câmara Municipal. Arquivo Municipal,jul.-dez. 2015), com a coordenação de André Teixeira, três publicações que resultaram de encontros científicos, designadamente $A$ conquista de Ceuta: Conselho Régio de Torres Vedras (Colibri \& Universidade de Lisboa, 2015), sob a minha coordenação, Ceuta e a Expansão Portuguesa (Academia de Marinha, 2016) e XVII Jornadas de Historia de Ceuta: Portugal y el Norte de África: Historias d'Aquem e d'Além-Mar (Instituto de Estudios Ceutíes, Ceuta, 2017), e, ainda, o excelente catálogo da exposição Lisboa 1415 Ceuta: historia de dos ciudades = história de duas cidades (Ciudad Autonoma de Ceuta \& Câmara Municipal de Lisboa, 2015). Creio que a temática é grandemente ignorada pela historiografia brasileira...

V. A. - Nas últimas décadas, o interesse pelos estudos medievais vem aumentando consideravelmente no Brasil. Como o senhor avaliaria a expansão da produção medieval portuguesa para o Brasil? Poderia indicar alguns destaques dos estudos medievais portugueses para os brasileiros?

C. G. - Remontando os estudos medievais à década de 40 do século XX, no Brasil, o país conheceu, de facto, nas últimas décadas, um incremento do número de professores e pesquisadores, que se dedica ao estudo da Idade Média. O salto ocorreu nos anos 80 , com a presença de professores franceses, italianos, alemães (no Sul) e portugueses, destacando-se, dentre os portugueses visitantes na Universidadede de São Paulo, Joaquim Barradas de Carvalho, que aí orientou dissertações e contribuiria, por exemplo, para a dissertação de doutoramento Lisboa, Personagem de Fernão Lopes 
(1983), da paulista e amiga Maria Lúcia Perrone de Faro Passos.

Mas a sua afirmação ocorreu apenas na década de 90, acompanhando o incremento da pesquisa em História Geral no âmbito dos programas de pós-graduação, tendo-se disseminado para o Rio de Janeiro e a partir daqui e de São Paulo, de um modo geral, por todo país. De igual modo, surgiram grupos de pesquisa e números de periódicos inteiramente dedicados aos estudos medievais, destacando-se, neste particular a revista Signum (1999-). E lembro aqui, entre outros, os trabalhos de Vânia Leite Fróes, Maria Sonsoles Guerras, José Rivair Macedo, Fátima Regina Fernandes, Maria Eurydice de Barros Ribeiro, Andréia Cristina Frazão da Silva, Ricardo da Costa, Leila Rodrigues da Silva, Carlos Roberto Figueiredo Nogueira, Lênia Márcia Mongelli e Hilário Franco Jr. Por outro lado, hoje encontra-se um cada vez maior número de jovens investigadores, que realizam o seu doutoramento em história medieval europeia, e mais especificamente portuguesa, como Bruno Marconi da Costa, que integra o Grupo de Estudos Medievais Portugueses (GEMPO), sobre a Lisboa Medieval. Registe-se, ainda, um também crescente número de livros sobre a Idade Média, de autores nacionais, assim como traduções de autores europeus, sobretudo da História dos Annales, como Jacques Le Goff e Georges Duby. Por último, para o incremento dos estudos medievais no Brasil terá contribuído decisivamente a criação da Associação Brasileira de Estudos Medievais (ABREM), em 1996. Portanto, o interesse pela área tem crescido, tendendo a afirmar-se na historiografia nacional, com estudos de qualidade.

Para a medievalidade, José Mattoso talvez seja o nome que os investigadores brasileiros melhor conheçam...

V. A. - Em relação aos estudos medievais, poderia pontuar algumas diferenças e semeIhanças entre a produção científica portuguesa e brasileira?

C. G. - Começo pelas semelhanças, reconhecendo que os estudos medievais, no Brasil, sofreram idêntica influência da Escola dos Annales, que a historiografia sobre a Idade Média portuguesa, com nomes como os já citados de Georges Duby e Jacques Le Goff, na sequência de outros como Marc Bloch e Henri Pirenne.

De igual modo, parece ser maior, em ambos os países, o número de trabalhos sobre a Baixa Idade Média em desfavor da Alta e Plena Idade Média, porque as fontes, manuscritas e impressas, são ali mais abundantes, e encontram-se na língua portuguesa, 
quando o latim, a língua dos documentos, grosso modo, até ao século XIII, é inacessível para muitos.

De modo distinto, a produção historiográfica brasileira sobre a Idade Média ainda se debruça muito sobre as fontes medievais literárias (romances, poesia, crónicas, anais) e jurídicas (tratados, as Ordenações), em virtude do seu acesso, por se encontrarem editadas. No fundo, são estudos que não têm, regra geral, por base fontes primárias de arquivo, pelo menos até há bem pouco tempo, acabando por condicionar a natureza dos estudos e a seleção dos temas, situação que tenderá a mudar em virtude da sua disponibilização em linha. É este contexto que explica o elevado número de dissertações em linguística, literatura e filosofia, quando comparado com o seu número em história.

V. A. - Professor Carlos Guardado, para finalizar nossa entrevista, o senhor poderia nos dizer no que está trabalhando, no momento, o que podemos esperar de suas próximas publicações?

C. G. - No que diz respeito à Idade Média, preparo a edição de uma coletânea de estudos sobre a cidade medieval, nomeadamente Lisboa e Torres Vedras, em que tem lugar um capítulo sobre as relações entre ambas, e o imaginário da floresta na Idade Média, que terá por título $A$ cidade e a floresta na Idade Média (Colibri), a editar em 2018.

Assim como me encontro a ultimar uma monografia coletiva sobre Torres Vedras, que percorre a história do território a partir do período romano e que, depois do século XII, traça a sua história século a século, a qual coordeno. Terá por título Torres Vedras. Nova História Local (Colibri, 2018), tendo eu ficado com a responsabilidade do período árabo-muçulmano e do século XII.

V. A. - Professor, na qualidade de medievalista, gostaria de deixar alguma mensagem aos pesquisadores da área?

C. G. - Apenas uma última nota ainda com o optimismo, que me caracteriza. Neste momento, com o acesso aos documentos arquivísticos, facilitado pelo facto de se encontrarem online, é o momento para os pesquisadores partirem para estudos sobre a Idade Média portuguesa tendo por base os documentos das chancelarias, maioritaria- 
mente publicadas para o período medieval, assim como muitos cartulários, e, se dispuserem de alguma prática em Paleografia, mergulharem na consulta e na leitura dos documentos manuscritos, disponívies em grande número em diversos arquivos, destacando-se, neste aspeto, o Arquivo Nacional Torre do Tombo (ANTT).

Estou certo de que, nos próximos tempos, fruto deste acesso, teremos mais e distintos estudos medievais brasileiros sobre Portugal, também facilitados pelas afinidades com a língua da documentação.

V. A. - Agradecemos em nome dos editores e demais colaboradores da revista Fronteiras \& Debates a sua atenção e contribuição.

C. G. - Sou eu quem muito agradece. Foi um enorme prazer! 